\title{
Immersive learning in nursing education: Results of a study
}

\author{
Liz Mary Ditzel ${ }^{* 1}$, Karole Hogarth ${ }^{1}$, Raewyn Lesa ${ }^{2}$ \\ ${ }^{1}$ School of Nursing, Otago Polytechnic, Dunedin, New Zealand \\ ${ }^{2}$ University of Otago, Dunedin, New Zealand
}

Received: October 30, 2016

DOI: $10.5430 /$ jnep.v7n5p120
Accepted: December 14, 2016 Online Published: January 10, 2017

URL: http://dx.doi.org/10.5430/jnep.v7n5p120

\begin{abstract}
Objective: This study evaluated the effectiveness of an immersive teaching and learning approach for undergraduate nurses. Traditional classroom tutorials were combined with self-directed learning using LabTutor ${ }^{\mathrm{TM}}$, an online learning platform, and clinical nursing simulation using high fidelity manikins. Learning modules were designed to link the student's knowledge and understanding of biosceince with clinical assessment and nursing management in order to develop clinical decision-making skills. It was anticipated that students' learning experience would be enhanced by the higher level of realism that is possible using the sophisticated manikins and authentic patient clinical data and case notes provided in LabTutor ${ }^{\mathrm{TM}}$.

Methods: The study took place in a New Zealand School of Nursing in 2014. Qualitative data was gathered using focus groups and an external facilitator. Quantitative data was gathered using an online survey.

Results: Participants were second year undergraduate nursing students $(\mathrm{N}=111)$ : $71(64 \%)$ interviewees, and $82(73 \%)$ survey respondents. Qualitative data showed that the immersive learning process was effective. Quantitative data affirmed that immersive learning was liked, confidence improved, students enjoyed the process, and would recommend it to others. Using simulation and patient case studies were preferred teaching strategies. Performing experiments, and using digital LabTutor ${ }^{\mathrm{TM}}$ technology challenged many, but skills improved over the year.

Conclusions: The immersive learning approach was effective. However, despite the high level of authenticity made possible by using high fidelity manikins, realism was hard to establish. An unexpected learning outcome occurred when intermittent technology malfunction prompted students to use problem-solving skills.
\end{abstract}

Key Words: Nursing education, Immersive learning, Simulation, Cases studies, Bioscience, LabTutor ${ }^{\mathrm{TM}}$, New Zealand

\section{INTRODUCTION}

The aim of this research project was to evaluate the impact of an immersive teaching approach combining traditional lectures, small group case-based tutorials, LabTutor ${ }^{\mathrm{TM}}$, selfdirected online learning and clinical simulation using high fidelity manikins, on second year undergraduate student learning in nurse education.

\subsection{Background}

Providing nursing students with opportunities to apply their classroom theory to clinical practice is foundational to undergraduate nursing education. ${ }^{[1]}$ However, the quality of learning opportunities on clinical placement is variable. Factors such as the student/preceptor relationship, busy work environments and patient's clinical presentations potentially influence students' learning opportunities. ${ }^{[1,2]}$ Additionally,

*Correspondence: Liz Mary Ditzel; Email: liz.ditzel@ op.ac.nz; Address: School of Nursing, Otago Polytechnic, Dunedin, New Zealand. 
patient safety is foremost in the clinical setting and must be maintained irrespective of whomever-a student or experienced nurse-is the caregiver. ${ }^{[3]}$ This responsibility and the ethics of 'practicing' on real people have prompted educators to investigate different ways to prepare today's nurses. ${ }^{[4]}$

Internationally, nursing schools have responded to such challenges by establishing simulated learning environments to teach students nursing skills, the responsibilities and the role of the nurse, and patient assessment and management. ${ }^{[5-7]}$ In New Zealand (NZ), the use of task trainers for clinical skill development, role-plays to teach professional skills such as communication and clinical simulation using low, medium and high fidelity manikins are well-established teaching methods. ${ }^{[1,8]}$ In our School of Nursing, a Year 2 simulation programme began in 2010. High fidelity manikins are used in two nursing scenarios: a post-operative hypovolemic patient, and a person suffering from chest pain of a cardiac origin, as core components of the medical and surgical nursing courses.

In 2012, LabTutor ${ }^{\mathrm{TM}}$, a digital learning platform was added to the Year 2 bioscience course. LabTutor ${ }^{\mathrm{TM}}$ offers online learning based around a video bank of case studies using actual patients and health care professionals. These are accompanied by real clinical data (e.g. diagnostic imaging and laboratory test results); associated physiology and pharmacology revision materials, and questions and prompts to explore the nursing needs and interventions of the indicial patient presented. Formal course feedback indicated students were highly satisfied with their learning experiences using LabTutor $^{\mathrm{TM}}$ learning technologies. The success of this initiative led to the redesign of our second year curriculum to provide a more contextualised learning experience. The aim was to use to use digital technologies in a blended approach to help students to link their bioscience knowledge and understanding of pathophysiology with clinical assessment and nursing management practice developed in simulation.

\subsection{Literature review}

Traditional lectures are a didactic and widely used form of teaching for large classes. ${ }^{[9]}$ They are an efficient way of delivering information and are frequently supported by visual technologies such as PowerPoint and voice recording systems so that students can review and revise content postdelivery. However, according to Craft et al., ${ }^{[10]}$ lectures are an inadequate strategy for teaching bioscience. Nursing students find the subject matter "content heavy" (p.115), and many feel uncomfortable or unable to approach the lecturer in a large class setting because of perceived power imbalances. Consequently, many students cope by rote learning and memorizing content. This is of concern to the nursing

Published by Sciedu Press profession as superficial learning impedes students' ability to integrate and apply bioscience knowledge to their clinical practice. ${ }^{[10,11]}$

Online learning is a student-centered, cost-effective teaching practice that provides students with increased flexibility and 24-hour access to course material. ${ }^{[9]}$ It alleviates problems that students may have attending classes on campus due to work schedules and family and other responsibilities. ${ }^{[10]}$ Our School of Nursing uses the digital platform 'Moodle' to deliver course content online. Students also complete self-directed learning activities to support knowledge development. Online learning complements other teaching methods such as small group tutorials and lectures.

In case-based learning (CBL) stories and real world examples are used to stimulate cooperative learning through discussion and problem solving. ${ }^{[12,13]} \mathrm{CBL}$ is student-centered, encourages motivation, engagement and the integration of knowledge and practice. ${ }^{[13-16]}$ Videoed case studies help students to engage with the characters and circumstances presented in the story while the teacher acts as a facilitator. Students respond positively to CBL and small group tutorials effectively support this mode of learning. ${ }^{[16,17]}$

LabTutor ${ }^{\mathrm{TM}}$ features both online and hands-on learning activities. ${ }^{[18]}$ Learning is based around clinical cases which are presented in multimedia format with video, audio tracks, medical imaging, laboratory results, and animations, graphical and textual components. Video segments are with the patients, families and key health care professionals. These filmed patient stories help students link their pathophysiology knowledge to real clinical cases. Hands-on activities feature laboratory sessions focused on measurement in humans. Students can use the optional classroom toolkit (supplied with LabTutor ${ }^{\mathrm{TM}}$ ) to perform experiments on themselves (e.g., individuals can record their heart rate and rhythm via three ECG leads) and then view the patients' results and compare them to their own usually health normal results. Content in LabTutor ${ }^{\mathrm{TM}}$ is accessible and flexible. An inbuilt authoring system allows the teacher to modify session, add or remove material of redesign form the beginning if they wish to so. LabTutor ${ }^{\mathrm{TM}}$ has been used successfully in our School of Nursing ${ }^{[19]}$ and in allied health settings. ${ }^{[20]}$ A recent UK study of first year nursing students $(\mathrm{N}=93)$ using LabTutor ${ }^{\mathrm{TM}}$ in bioscience found that although a few felt anxious about computer-based learning, the majority enjoyed using the equipment to learn and confidence improved. ${ }^{[21]}$

Clinical simulation is a form of active learning designed to convince users that they are engaged in a real-time clinical situation. ${ }^{[22]}$ Simulation practice has rapidly developed after the introduction of computer controlled whole body manikins 
known as high fidelity simulation (HFS). ${ }^{[22,23]}$ (Fidelity is the term used to describe the precision or reproduction of real life). Nurse educators create or use pre written scenarios involving the life-sized, computerised manikin as a 'real patient' in a hospital bed or relevant clinical environment such as a clinic. During the simulation encounter students are usually assigned a role such as a nurse, family member, or observer and are given guidelines and expectations for these roles. ${ }^{[22]}$ HFS creates a learning environment that improves students' knowledge, psychomotor skills, safety, confidence, competence and satisfaction with learning. ${ }^{[2]}$ A number of systematic and integrative reviews have examined clinical simulation and nursing education. ${ }^{[25,26]}$ Simulation has many advantages. Learning can take place without risk to patients. Students can be allowed to make mistakes and learn from these. Practical skills are developed in a systematic, supported way. ${ }^{[23-26]}$ Simulation appeals to technologically savvy students who may prefer it to more passive, linear modes of learning. ${ }^{[23,27]}$ The manikin fidelity is an important element in the scenarios but setting the right scene and having a well-designed clinical case are equally important to achieving student learning outcomes. Less favourable aspects of simulation relate to high anxiety levels and a dislike of being observed especially among novice students. ${ }^{[28]}$

Immersive learning is a strategy where learners are located in place that closely represents the 'real world' so that they can fully experience the sounds, smells, sight and physical aspects of that environment. ${ }^{[29]}$ Shön ${ }^{[30]}$ described this as a practicum, a place where disbelief is suspended as the learner becomes an actor as part of the scene. Immersive and simulation-based technologies contextualise learning by providing the student with opportunities to use medical equipment and interact with the people in an encounter that closely replicates an actual nursing situation. ${ }^{[29]}$

\subsection{The immersive learning process}

Using the following steps, two immersive learning modules were developed to assist students to link theoretical concepts with clinical practice.

(1) Theory lecture and directed online learning (OLL): theory content is delivered via a traditional lecture. Students then complete self-directed study online that involves meeting the person by way of a video case study presentation and looking at the pathophysiology of the person's condition.

(2) LabTutor session: students come to the LabTutor ${ }^{\mathrm{TM}}$ classroom in groups and conduct a physiological experiment and compare their own data to that of the person with the disease process (hands on learning).

(3) Group tutorial: students continue looking at the case and discuss and link physiological data with the nursing management of the case they have observed in LabTutor $^{\mathrm{TM}}$.

(4) Simulation: students work in groups of four to provide nursing assessment and care for the person in the simulation laboratory (Integrates steps 1, $2 \& 3$ ).

(5) Debrief and reflection: students debrief (discuss using a structured format) the simulation and complete a directed learning worksheet about the case.

Figure 1 shows the steps of the learning design that was presented to students on the course home page on Moodle, a digital learning platform.

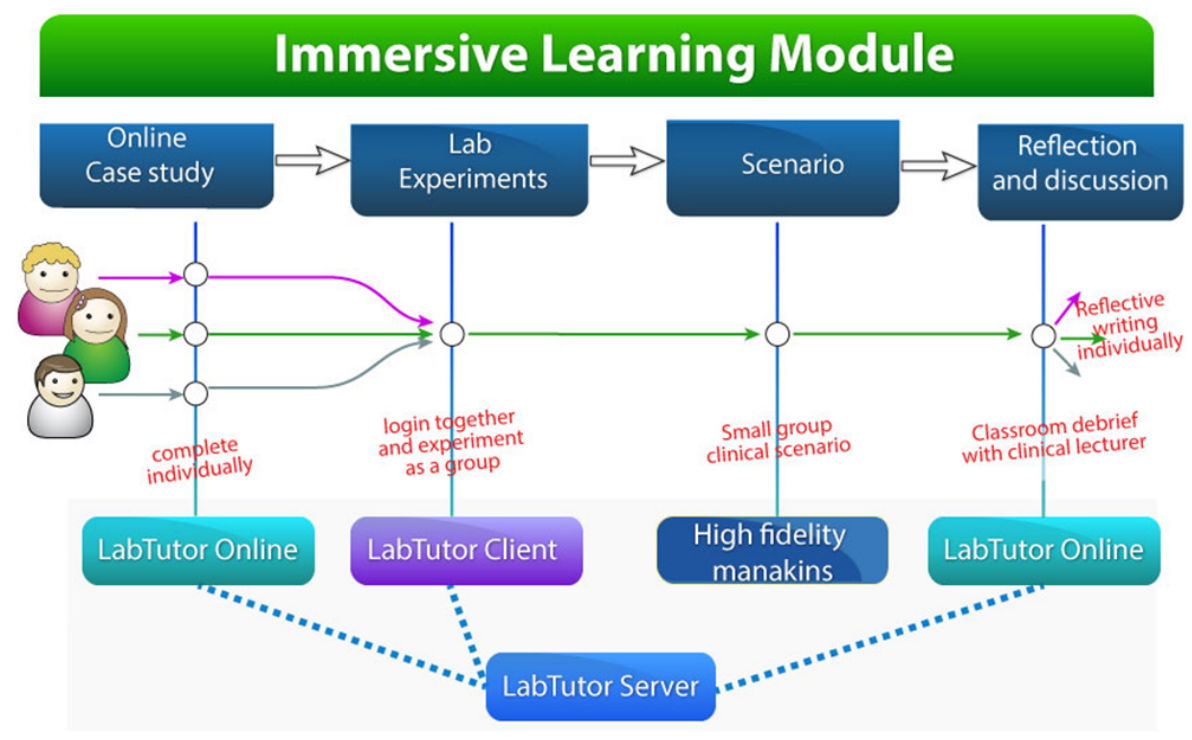

Figure 1. The immersive learning module 


\subsection{Learning modules}

Two case studies were developed, a patient who has a cardiac arrest following a myocardial infarction (the MI case) and a patient admitted to hospital with an acute exacerbation of Chronic Obstructive Pulmonary Disease (COPD, the COPD case). The students were able to use the relevant information from the videos and clinical investigations to assess and intervene during the simulated learning experience which involved the previously seen case study patient they had observed. The patient case integrates the learning experience and was used to guide the debriefing session.

\section{METHODS}

\subsection{Study setting and participants}

This study was conducted in a School of Nursing in NZ in collaboration with ADInstuments (ADI), an international medical education company who supplied the two Gaumard high fidelity manikins used in this project. Staff worked together to develop and implement the two immersive learning modules used for this study. An academic (LD) not involved in teaching the course led the research team. LabTutor ${ }^{\mathrm{TM}}$ sessions were conducted by a senior academic $(\mathrm{KH})$, supported by an ADI staff member, the School of Nursing technician and others. The course instructor (RL) and other staff members facilitated simulations and debriefing. The research team met at regular intervals to review the key themes, and identify matters requiring solutions.

Research participants were second year nursing students (N = 111) split into four teaching groups (A, B, C, D). Students were further divided into smaller subgroups, i.e., group A into A1 \& A2, etc. for tutorials and simulation. Each group had the same immersive learning experience, but at different times of the academic year.

\subsection{Study methods}

The mixed method study was conducted in two phases over the academic year. An action research methodology ${ }^{[31]}$ was used to identify and resolve problems, such as students not being able to logon to the learning modules, as they arose. Informed consent was gained from the participating students. Qualitative data was gathered using focus groups and an external facilitator. Group sessions were approximately 50 minutes long, digitally recorded, then transcribed by an administrator who signed a non-disclosure confidentiality agreement. Participants also used a simple scoring sheet to rate their satisfaction with the different teaching and learning components at the end of the interview. Four questions were used to structure each focus group session:

(1) Overall, how effective did you find the immersive style of learning?
(2) How effective did you find the learning relating to the MI and COPD case study?

(3) How much did you like this as a style of learning?

(4) What was your general perception of this style of learning?

Quantitative data were gathered at the end of the study using an online questionnaire that was designed by the research team with input from ADI staff. The study was advertised during lectures. The online survey was accessible through a secured institutional course portal. It included 26 forcedchoice and 8 open-ended questions. Different response indicators were used for the different items, but for all statements, 1 equalled the highest level of agreement or satisfaction, and 5 the lowest level. Limited demographic data (age, gender) was also collected.

\subsection{Ethical considerations}

The institution's Research Ethics Committee Ethical approved this study (OPREC 2014-577). Students signed confidentiality and consent forms for participating in the simulation scenario and each phase of the research study respectively. Data were de-identified prior to analyses. Participants were made aware that taking part in this study was voluntary and they could withdraw at any time. They were also assured that their responses would remain confidential and that participating in this study was not part of course assessment and would have no bearing on their course grades.

\subsection{Data management and analysis}

The project leader and interviewer reviewed the transcripts after each focus group session to identify commonly expressed themes. Themes were then verified through a pen and paper content analysis. ${ }^{[32]}$ The online survey was pilot tested by the research team before going live in the last week of November. De-identified data were returned as a computer generated summary report of simple descriptive statistics. Research team members manually coded the open-ended responses to identify common themes. Study data is only accessible by the named investigators and all records will be kept for the time period mandated by organisational protocol. Paper files will be shredded and computer files deleted.

\subsection{Sample}

A total of 71 students (64\%) participated in focus group interviews. These were held soon after each immersive learning experience and occurred in six cycles; Cycle 1 (April; $\mathrm{n}=$ 13), Cycle 2 (May; $n=8$ ), Cycle 3 (June; $n=10$ ), Cycle 4 (September; $n=22$ ), Cycle 5 (October, $n=12$ ), Cycle 6 (November; $\mathrm{n}=16$ ).

Eighty-two students (73\%) completed the online survey. The 
majority of these respondents were female (male $=95 \%)$; nearly two thirds $(61 \%)$ were in the $18-21$ year age group; $23 \%, 9 \%$ and $2 \%$ respectively, were in the $22-25,26-30$, and $31-45$ year age groups.

\section{RESULTS}

Focus group interview results are presented under the five headings identified from the thematic analysis. Quantitative data relating to the overall effectiveness and general perceptions of the immersive learning process is summarised in Table 1 and Figure 1. Themes from the online survey's open ended questions are summarised in Table 2.

\subsection{Focus group themes}

Five themes were identified. They relate to the key elements of the immersive learning design. Student comments are direct quotations and reported in italics.

\subsubsection{Teaching and learning}

The dominant theme relating to student's teaching and learning experiences was captured in the first cycle by the comment - "go over it, get it, see it!" indicating that elements of the immersive learning model worked together to reinforce learning. For example, "actually breathing and pretending we had COPD is really good. I could feel the difference", shows that this experience helped students to understand the pathophysiology of COPD. The theory lecture "added a lot, it actually made me understand the concepts more". Online learning activities where "you had to match the diagram with the part of the heart belonged to that name, activities like that", were reported as preferable to "just reading and questions". Seeing the video vignettes of the person with the condition also enhanced students' learning because it helped to connect the learning activities and the person, leading into the simulation.

"We learned about the disease during the lecture, and then we watched video on somebody who had the disease, and listened to them talking about their own experience with it and what that meant for them and how it affected their life and also their relatives."

The following comment indicated that students valued the immersive aspects of their learning experience.

"I thought it was very interesting... having the activities immersed in the middle of each thing was nice to be able to test yourself and then you could go back and check it. It's nice for us to go back and ... I was actually taking it in and it was real nice".
However, these connections were not as explicit in the fourth cycle, rather students perceived there to be repetition, typified by this statement "the bits that were linked repeated themselves a lot". Hopefully, this comment reflects the fact that students were near the end of their second year course work and were better informed!

Overall, comments such as "this will never escape my mind again!" and "it was good getting to see the patient and see how it all connected - which I like, to follow through all of it", indicated that the immersive process, especially seeing the videos and following an actual patient, worked as an effective teaching strategy. This is summed up by the following comment:

"For me it was how she was expressing her mind telling me how she is feeling, telling us how long she had been smoking before she stopped. How she breathes when she is going for exercise and gets out of bed. I keep remembering it in my brain, I can't forget it'.

\subsubsection{Case study tutorial}

Students valued working in small group tutorials where they reviewed the case study, discussed and linked the physiological data gained from the LabTutor ${ }^{\mathrm{TM}}$ experiment with nursing management of the person with the medical condition. This sentiment is captured by this student's comment "I thought the tutorials were the best part of everything that was the best step out of all the 5". Participating in the tutorials provided a safe learning environment that encouraged students to ask questions relating to the case study.

"K brings her personal stories as well... the history of the patient, not just focus on how they are presenting-like test results and stuff we don't usually get a chance to interpret. We can ask lots of questions. It's good for me because I like to be able to ask questions in a small group-not in a whole lecture room".

Despite technological issues, which were attended to over the year, learning experiences using the case studies were beneficial. Students could link pathophysiology relating to the person's condition and the simulated nursing scenario involving the person presented in the LabTutor ${ }^{\mathrm{TM}}$ video.

"I think it was pretty good how you can meet the patient first so you've got that... identifying a person and them you get the anatomy and other stuff behind it and that reinforces it a bit more".

Learning experiences for both cases varied although the MI case was preferred as it was "really easy to do with lots 
of videos". Many found the COPD case "confusing" and "complex with things like lung capacity" and were uncertain about how to perform the associated spirometry experiments. Reading technical language relating to the experiments challenged those who "weren't quite sure what the figures meant and what we were supposed to do with them". In the last cycle, appreciation for using case studies was evident.

"I found the case study really good because you could physically see someone with the disease process and see the symptom physically which really helped match it up... That was really helpful....the real patients who actually had the diseases".

\subsubsection{LabTutor $^{T M}$ experiment}

Using the online LabTutor ${ }^{\mathrm{TM}}$ technology presented challenges throughout the year. Many students had forgotten passwords, others reported not knowing what to do or being unfamiliar with navigating the learning platform. One participant said, "at the start of our first LabTutor session, a lot of people couldn't get online, it wasn't working or something". Navigating the LabTutor ${ }^{\mathrm{TM}}$ menu and using the resources was also difficult for some who "found it challenging to get my head round the layout of the LabTutor and I'd like to have more drag down options to use". On the positive side, the LabTutor ${ }^{\mathrm{TM}}$ learning resources especially enjoyed were: "Real live case studies with actual patients" and "interviews and stuff with them".

In the second cycle, students had just returned from a semester break and some experienced difficulties accessing the online learning resources. At the same time, building and construction activities in the floor immediately below the School disrupted the learning environment, affected the wireless technology and caused problems with the functionality of the manikin.

"[There was] a bit of a mix up in our first week... the programme hadn't been opened up to us yet... there was no real guidance, like it was here's your computer, log in, read whatever is on the screen... for me that doesn't work... A lot of us couldn't sign in".

For some, performing the experiments was challenging. "We had the pulseometer on too, and doing relationships between the ECG and what we got. But we didn't really see how it had much to do with the MI". On the positive side, face-toface teaching and the presence of a tutor in the classroom provided an opportunity for clarification of content.

"And $\mathrm{K}$ our tutor was with us helping... She talked us through it. It was the same content but

Published by Sciedu Press she just explained it more in-depth... She was going through it on the screen".

\subsubsection{Simulation}

Performing a simulated nursing scenario was not a new experience as all students had completed one in their first year. Students worked in groups of three to four for each scenario. In the Simulation Suite there were usually three roles (registered nurse, student nurse, relative sitting at the bedside) and outside the suite, an observer viewing the simulation through the one-way mirror. Performing these different roles, particularly that of relative provided them with valuable insights. However, many reported being "a bit lost at sea"; that they did not know what to do, or were unprepared for this simulation experience. A typical comment follows:

"We needed more information on the nursing intervention... we knew about the disease, this happens in the body, we weren't given what nurses are supposed to do with that-we weren't given the next step".

Making the simulation look and feel like a real clinical nursing experience was critical to the immersive learning design. Realism however, was not always easy to achieve. While some were "blown away when manikin went into cardiac arrest", others found the simulation less realistic.

"Just because it was, like, you're fine; you're talking to a patient, everything is going well. Then all of a sudden and they flat line, and it just doesn't-very rarely does it happen like that. There's lots of warning signs usually before somebody just crashes like that".

A factor that did help the scenario appear more real was the voice communication via microphone when staff responded to student questions (or gave prompts) during the simulation. Some students did not like being watched and found the experience "quite stressful" and others were reassured by the fact that they were in a Simulation Suite.
"The safety of knowing if you screwed up in the simulation nothing happens but you really know what you've done wrong, so you know what to do next time when you're actually out there".

\subsubsection{Debrief}

The post-simulation debrief is a critical part of the learning experience as it provides feedback on performance and reassurance for students. The debrief was rated as "very helpful", "reassuring", and the "best part", assisting learning because: 
"You talk about the strengths and weaknesses of everybody working together and what you did really well, and what you could have improved on, and you get to discuss it with who you were working with, with input from the lecturer".

Over cycles 3-6, the manikin's performance was affected by intermittent internet wireless 'drop out' beneath the Simulation Suite. Students used the term "negative learning" to describe what happened when the manikin did not operate properly (e.g., the manikin's eyes kept on blinking but he had no pulse). The following comments tell the story of the 'dead' manikin continuing to breathe after an unsuccessful resuscitation.

"It's a manikin, so you don't see it go unconscious. It doesn't have an expression on its closed eyes... it was still breathing... it was confusing. And if he hadn't been breathing, we would have known what was happening, it we had seen that it and then we should have been able to do it."

Eventually 'Hal', the manikin failed to work properly: "the machine turned off, but we thought it had died so we didn't know what to do". But, with prompts and reassurance from staff in the Simulation Suite, students found the simulation experience useful, and (maybe because of the breakdown) the sequence of events and roles played resembled a real situation.

"The experience seemed the same as a real one except there were a whole lot more people around; there was doctors, registrars, crash team, like everyone".

For some, the scenario seemed real due to the pre-learning, familiarity with the person's conditions and the roles played in the simulation activity.

"It's a lot more realistic having the videos beforehand, compared to other simulation where you just do the pre-reading and them we go in and it's just a dummy, and they are saying this is what the dummy's got and go and do your simulation".

Students identified two areas for improvement: "the nursing intervention side of things: tweaking some of the software stuff in terms of the whole log in business".

\subsubsection{Assessment of overall effectiveness}

At the end of each focus group session, participants rated their responses to four questions. Table 1 summarises the ratings for Q1: How effective did you find each part (listed as 1 to 5 in the table) of the immersive style of learning? The scale used is $1=$ low, and 5 = highly effective.

Table 1. Overall effectiveness of immersive style of learning $(\mathrm{N}=71)$

\begin{tabular}{llll}
\hline \multicolumn{2}{l}{ Items } & COPD & MI \\
\hline 1. & Theory lecture and on line learning & 3.9 & 4.03 \\
2. $\quad$ LabTutor session & 3.71 & 4.09 \\
3. Group tutorial & 4.12 & 4.12 \\
4. Manikin simulation and debrief & 4.06 & 2.92 \\
5. Post simulation written reflection & 2.83 & 2.17 \\
Averaged score & $\mathbf{3 . 7 2}$ & $\mathbf{3 . 4 7}$ \\
\hline
\end{tabular}

Table 1 shows that students preferred the COPD case study as effective learning over MI. Overall, the group tutorial is the most highly rated learning style for COPD and MI. Written learning is lowest rated for both. Students were also asked how much they liked, and their general perception of the immersive style of learning. Responses are summarised in Figure 2.

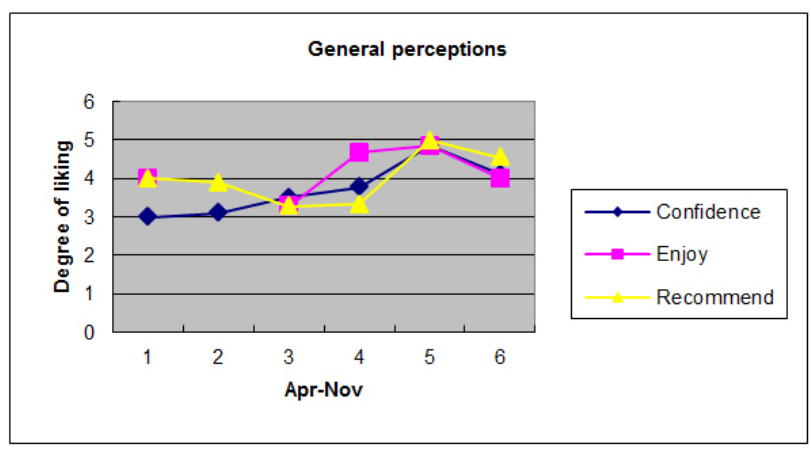

Figure 2. General perceptions of the immersive learning process

Figure 2 summarises student perceptions of the immersive learning process; confidence improved, students enjoyed the process, and would recommend it to others. Positive responses grow over the year for confidence, enjoyment, recommend to others.

\subsection{Online survey results}

Table 2 summarises themes identified from the open-ended responses to the online survey conducted at the end of the academic year. 
Table 2. Themes from the open-ended responses to the online survey

\begin{tabular}{ll}
\hline Questions & Responses \\
\hline & Simulation (24) \\
What was the most valuable part of the immersive learning & Debrief/reflection (20) \\
experience? & Case study and pre-case learning (15) \\
$(\mathrm{N}=82)$ & Videos/real life scenarios (13) \\
& Tutorials (10) \\
& Technology not working/too challenging or difficult (20) \\
What was the least valuable part of the immersive learning & Experiments (15) \\
experience? & Lack of staff support/help in labs (5) \\
(N = 51) & Time consuming (4) \\
& Manikins - not that real (4) \\
& Play acting in an unreal scenario (3) \\
\hline
\end{tabular}

These responses show that the most valuable part of the immersive learning experience for students was the simulation and associated debrief/reflection, closely followed by the case study; and the least valuable aspect, the various problems and challenges relating to using the technology and performing the experiments.

\section{Discussion}

Our findings clearly demonstrated that the immersive learning approach was effective for second year nursing students. Qualitative data showed that the interrelated aspects of the immersive process, i.e., the case material, video clips and small group tutorial discussion helped students to understand and link the pathophysiology to the clinical presentation and patient's experience of their medical condition. Quantitative data affirmed that this form of learning was liked, confidence improved, students enjoyed the process, and would recommend it to others. Using simulation supported by visual teaching media such as patient case studies was the preferred teaching strategy. Performing experiments, using the LabTutor ${ }^{\mathrm{TM}}$ learning platform and associated technology challenged many, but skills improved over the course of the year.

\subsection{Simulation using high fidelity manikins}

The importance of simulation technology as an educational and evaluative tool is well established. ${ }^{[25]}$ It is an effective tool that enhances cognitive development and provides students with opportunities for authentic learning in a safe environment. ${ }^{[26]}$ Findings from the focus groups supported by comments made in the open-ended survey indicate that simulation is beneficial to development of decision-making and practical nursing skills in both scenarios. This result concurs with others who established that simulation enhances best practice in clinical learning. ${ }^{[33-35]}$ Simulation also fosters collaborative learning and increase student confidence in critical scenarios, while identifying gaps in student knowledge

Published by Sciedu Press that may have gone unrecognised. ${ }^{[12,36]}$

Using computer controlled high fidelity manikins to simulate patient responses provides students with opportunities to practice skills knowing that the recipients of their care patients are safe, thereby lessening anxiety. ${ }^{[37,38]}$ The Gaumard high fidelity manikins were chosen because their software programs can be programmed to replicate the signs and symptoms of a medical event such as a cardiac arrest (as a consequence of an MI). For example, in the MI scenario, vital signs change to reflect the hemodynamic changes experienced with compromised heart function. It is possible to show changes of cardiac ischemia on the patient monitor and cyanosis is evident when the skin tone on the manikin's face turns blue. The nurse can also take vital signs (blood pressure, pulse, respiratory rate) and perform other tests such as an oxygen saturation reading taken on the manikin's finger by way of an electronic sensor.

The case study and simulation gave students a chance to "have a practice run at what to do in a real life situation" as they were required to assess, evaluate and responding to a person experiencing the signs and symptoms of a myocardial infarction and then perform Cardio Pulmonary Resuscitation (CPR). The underlying teaching and learning pedagogy of using a simulated scenario is to provide leeway for students to make 'safe mistakes' is well established in the literature. ${ }^{[33-36]}$ Furthermore, in this study it was anticipated that students' learning experience would be enhanced by the higher level of realism that is possible using these manikins, supplemented by authentic clinical data and patient case notes.

Realism however was not well established. In the first half of the year, most participants referred to the manikin as "the dummy" suggesting that the transference or the person's identity (shown in the case study) was not occurring. However, later in the year when the manikin broke down, this term was 
seldom used. So called 'negative learning' occurred when the situation did not make sense to the students (or work out as it should have done). Paradoxically, the situation of the unconscious (or dead) but still blinking manikin provided the best teaching material for staff leading the debriefing discussions, as the manikin malfunction provided the perfect opportunity to reflect upon this experience and to use problem solving and critical thinking skills to investigate this unexpected situation. Negative learning also occurred when there was a lack of integration within learning components. Where the sequence of immersive learning tasks, such as the link from online to practical implementation was unclear to students, they reported impeded progress and lowered confidence in understanding.

Overall, students reported improved levels of confidence in learning by simulation and particularly valued the debriefing process; this provided reassurance and a boost to confidence. The key to simulation is debriefing involving abstract conceptualisation and reflective observation. Reflection and debriefing provide academics and students with the opportunity to examine action and decisions and allows the educator to correct errors, clarify mistakes, receive student feedback and exercise effective safe nursing care. ${ }^{[5]}$ Neil and Wooton ${ }^{[39]}$ state that "debriefing is a strategy nursing educators need to master, as efficacious debriefing frameworks can enhance student learning". Students appreciated the benefits of receiving feedback on their performance and they learned from their own mistakes and those of others, feedback from academic staff helped them to understand the nursing process and the responsibilities commensurate with a second year student nurse's role. This concurs with the findings of Shinnick et al. ${ }^{[40]}$ who asserted that feedback is essential as a process of reflection that is required to contribute to the transformation of knowledge into practice skill.

\subsection{Case studies}

Case based learning (CBL) has a long history is nursing education and the research suggests that it is an effective method of learning for nursing programmes and subject specific programmes such as pharmacology. ${ }^{[41]}$ The case studies presented in LabTutor ${ }^{\mathrm{TM}}$ programme were specially designed and produced for the School of Nursing. They were produced to provide an interactive learning technology that was relevant to the millennial learner. The two people presented in the video case studies were filmed in their own homes and in the hospital setting. Using visual media brought the cases to life; students got to know the person and could see health practitioners performing procedures, for example, a registered nurse taking an Electrocardiograph. Using video case studies is a widely supported strategy in nurse education. ${ }^{[42]}$
This more accessible format (compared to a paper-based case study) enhanced students' interest and enabled a better understanding of the person's medical condition. Research supports the use of cases that involve the student in realistic assessment and problem-solving. ${ }^{[3,44]}$ As found in our study, cases encourage integration of knowledge and practice and development of learning skills. Students could articulate theory practice links, as has been demonstrated by others. ${ }^{[43,45]}$ Learning experiences for both cases were positive, although students preferred the MI case, the COPD case was rated as the most effective.

\subsection{LabTutor $^{\mathrm{TM}} /$ Experiments}

Apart from Swift et al.'s recent study, ${ }^{[21]}$ there is limited research into the efficacy of LabTutor ${ }^{\mathrm{TM}}$, particularly research focusing on undergraduate nursing education. These results show that LabTutor ${ }^{\mathrm{TM}}$ is an effective teaching and learning platform, notwithstanding student difficulties in logging on and initial problems with using the drop down menu. The benefit of this technology is that it allows students to use online tools to learn at their own pace, and to revise where necessary. This caters for the needs of the millennial learner and once operational glitches were remedied, it is a reusable and sustainable educational tool.

One of the advantages of using LabTutor ${ }^{\mathrm{TM}}$ is that users can perform simple experiments on themselves. For example, users can learn about respiration using a spirometer to measure their own breathing rate, flow and volume. These hands-on learning activities were designed to help students to understand the pathophysiology underpinning the medical conditions presented in the case studies and to provide insights into how a person with COPD lives with the symptoms of such a debilitating condition, i.e., a restricted lung capacity, increased respiratory rate and lower inspiratory volume. However, much to the disappointment of staff who considered the experiments integral to the immersive learning design, performing the spirometry experiments for the COPD case along with reading and interpreting ECGs proved challenging for many students. This situation could have been remedied by providing more staff to assist in the LabTutor ${ }^{\mathrm{TM}}$ class. Finally, as the study progressed it became obvious that staff also required further development of their technology skills to guide student learning effectively.

\section{Conclusion}

Nurse educators know that students find bioscience courses challenging but such knowledge is essential to monitor and assess their patient's clinical condition, and interpret that information to determine the most appropriate course of action. Active learning and small group sessions are typically 
used to counter these difficulties. Our teaching approach integrated traditional instructional methods with digital learning technologies and clinical simulation. Two learning modules were designed to help students to integrate their knowledge of pathophysiology (taught in a bioscience course) with clinical assessment and nursing management (taught across the curriculum) and practiced in simulation.

Our findings clearly demonstrate that the immersive teaching and learning approach was effective for second year nursing students. Using simulation and patient case studies were preferred teaching strategies. Seeing the videos embedded in LabTutor ${ }^{\mathrm{TM}}$ helped students to link pathophysiology relating to the person's condition and the simulated nursing scenario. Simulation using high fidelity manikins can support student nurses to provide excellent nursing care. A carefully designed simulation resembles a sophisticated role-play, links theory and practice, and allows students to experience the outcomes of their decisions. Yet, the question of realism remains.
High fidelity manikins were chosen to make the replicated simulation look and feel real. Nonetheless, technological glitches occurred and realism was difficult to establish. Initially, students referred to the fully functional manikin as the "dummy". However, as often happens in the real world of clinical practice, staff and students were provided with the most valuable immersive learning experiences when the manikin failed to work properly. These events greatly enhanced realism, and prompted students to use problemsolving skills.

\section{ACKNOWLEDGEMENTS}

The authors would like to acknowledge the support of AD Instruments, receipt of an AKO Aotearoa Regional research grant and thank the students who contributed to this evaluation study.

\section{CONFLICTS OF INTEREST Disclosure}

The authors declare that there is no conflict of interest.

\section{REFERENCES}

[1] Spence D, Valiant S, Roud D, et al. Preparing registered nurses depends on "us and us and all of us". Nursing Praxis in New Zealand. 2012; 28(2): 5-13. PMid:23029783

[2] Disler RT, Rochester SF, Kelly MA, et al. Delivering a large cohort simulation - beginning students' experience: A pre-post survey. Journal of Nursing Education and Practice. 2013; 3(12): 133-142. https://doi.org/10.5430/jnep.v3n12p133

[3] Chan DS. Associations between student learning outcomes from their clinical placement and their perceptions of the social climate of the clinical learning environment. International Journal of Nursing Studies. 2002; 39(5): 517-524. https : //doi .org/10.1016/S0020-7 489 (01) 00057-8

[4] Hayden JK, Smiley RA, Alexander M, et al. The NCSBN National Simulation Study: A longitudinal, randomized, controlled study replacing clinical hours with simulation in prelicensure nursing education. Journal of Nursing Regulation. 2014; 5(2): S3-S40. http://dx.doi.org/10.1016/S2155-8256(15) 30062-4

[5] Jeffries PR. Simulation in nursing education: From conceptualization to evaluation: 2012; 2nd ed. National League for Nursing.

[6] Leighton K, Johnson-Russell J. Innovations in facilitating learning using simulation. In Bradshaw MJ and Lowenstein AJ. Innovative teaching strategies in nursing and related health professions. 6th ed. Burlington, MA: Jones \& Bartlett Learning; 2013. pp.239-265.

[7] Bailey C. Human Patient Simulation. In Bradshaw MJ, Lowenstein AJ. Innovative teaching strategies in nursing and related health professions. 6th ed. Burlington, MA: Jones \& Bartlett Learning; 2013. 203-224p.

[8] Wordsworth A. Realising the potential of simulation: Integrating simulation into nursing programmes at Whitireia New Zealand. Whitireia Nursing and Health Journal. 2013; 20(Nov). https://search.informit. com.au/documentSummary; dn= 756668885373458; res=IELHEA

Published by Sciedu Press
[9] Schunk D. Learning theories. An educational perspective. 2012; 6th ed. Pearson, Boston MA.

[10] Craft J, Christensen M, Bakon S, Wirihana L. Advancing student nurse knowledge of the biomedical sciences: A mixed methods study. Nurse Education Today. 2017; 114-119. http://dx.doi .org/10. 1016/jnedt.2016.10.003

[11] Bakon S, Craft J, Christensen M, et al. Can active learning principles be applied to the bioscience assessments of nursing students? A review of the literature. Nurse Education Today; 2016; 123 127. PMid:26775033 http://dx.doi.org/10.1.16/jnedt. 201 5.11 .030

[12] Kaddoura MA. New graduates nurses' perception of the effects of clinical simulation on their critical thinking, learning and confidence. Journal of Continuing Education in Nursing. 2010; 41(11): 506-516. PMid:20672760 https ://doi.org/10.3928/00220124-20100 701-02

[13] DeMarco R, Hayward L, Lynch M. Nursing student's experiences with and strategic approaches to case-based instruction: A replication and comparison study between two disciplines. Journal of Nursing Education. 2002; 41(4): 165-174. PMid:11954968

[14] Daily MA. Developing case studies. Nurse Educator. 1992; 17(3): 811. https://doi.org/10.1097/00006223-199205000-00009

[15] Kaddoura MA. Critical thinking skills of nursing students in lecturebased teaching and case-based learning. International Journal for the Scholarship of teaching and Learning. 2011; 5(2). Available from: http://www.georgiasouthern.edu/ijsotil https:// doi.org/10.20429/ijsotl.2011.050220

[16] Dowd SB, Davidhizar R. Using case studies to teach clinical problem solving. Nurse Educator. 1999; 17(3): 8-11. https ://doi .org/10 .1097/00006223-199909000-00017

[17] Curran VR, Sharpe D, Forristall J, et al. Student satisfaction and perceptions of small group process in case-based professional learn- 
ing. Medical Teacher; 2008; 431-433. PMid:18569668 https: //doi.org/10.1080/01421590802047323

[18] AD Instruments. LabTutor for nursing education. Connecting physiology with nursing care. Available from: http://cdn.adinstruments.com/adi-web/brochures /LT_for_Nursing_Brochure.pdf

[19] Hogarth K. Implementation of LabTutor into nursing bioscience teaching. Australasian Nurse Educators Conference, 2013; Wellington, NZ.

[20] Fell J, Allen M, Douglas T, et al. The implementation of LabTutor $\AA$ teaching systems in physiology practical classes. nd. Available from: http://www.utas.edu.au/__data/assets/pdf_file /0004/167377/Session1a-FS2-Douglas.pdf

[21] Swift A, Efstathiou N, Lameu P. Is LabTutor a helpful component of the blended learning approach to biosciences? Journal of Clinical Nursing. 2016: 25: 2683-2693. https://doi.org/10.1111/jo cn. 13175

[22] Jeffries PR. The NLN Jeffries Simulation Theory. 2016: National League for Nursing. Wolters Kluwer, NY.

[23] Harder BN. Use of simulation in teaching and learning: A review of health sciences. Systematic Review of Simulation Use. 2010; 49(1). https://doi.org/10.3928/01484834-20090828-08

[24] Cant RP, Cooper SJ. Use of simulation-based learning in undergraduate nurse education: An umbrella systematic review. Nurse Education Today. 2017; (49): 63-71. http://dx.doi.org/10.1016.11.01 5

[25] Nehring WM, Lashley FR. Current use and opinions regarding human patient simulators in nursing education: An international survey. Nursing Education Perspectives. 2004: 25(5): 244-248. PMid:15508564

[26] Motola I, Devine LA, Chung HS, et al. Simulation in healthcare education: A best evidence practical guide. AMEE Guide No. 82 Medical Teacher. 2013; 35: e1511-e1530. http://dx.doi.org/1 $0.3109 / 0142159 X .2013 .818632$

[27] Hampton DC, Keys Y. Generation Z students: Will they change our nursing classrooms? Journal of Nursing Education and Practice. 2017; 7(4): 111-115. http://dx.doi/org/10.5430/jnep.v7n4 p111

[28] Szpak JL, Kameg KM. Simulation decreases nursing student anxiety prior to communication with mentally ill patients. Clinical Simulation Nursing. 2013: 9(1). http://dx.doi.org/10.1016/j.ecn s.2011.07.003

[29] Roberts D, Mason J, Williams E, et al. Promoting empathy through immersive learning. Journal of Nursing Education and Practice. 2016; 6(8): 1-9. http://dx.doi.org/10.5430/jnep.v6n8p1

[30] Schön D. Educating the reflective practitioner. 1978. Jossey-Bass, San Francisco.

[31] Rierson IA, Hvidten A, Wighus M, et al. Key issues and challenges in developing a pedagogical intervention in the simulation skills center - An action research study. Nurse Education in Practice; 2013: 294-300. PMid:23642302
[32] Nagy S, Mills J, Waters D, et al. Using research in healthcare practice. Wolters Kluwer Lippincott/Williams \& Wilkins Broadway, NSW, Australia. 2010; pp143-145.

[33] Neilson A, Noone J, Voss H, et al. Preparing nursing students for the future: An innovative approach to clinical education. Nurse Education in Practice. 2013; 13: 301-309. PMid:23591129 https: //doi.org/10.1016/j.nepr.2013.03.015

[34] Meakim C, Boese T, Decker S, et al. Standards of best practice: Simulation standard I: Terminology. Clinical Simulation in Nursing. 2013; 9(6): S3-S11. https://doi .org/10.1016/j . ecns . 2013. 04.001

[35] Lasater K. High-fidelity simulation and the development of clinical judgment: Students' experiences. Journal of Nursing Education. 2007; 46(6): 269-276. PMid:17580739

[36] Luckter-Fleude M, Baker C, Pulling C, et al. Evaluating an undergraduate interprofessional simulation-based educational module: Communication, teamwork, confidence performing cardiac resuscitation skill. Advances in Medical Education in Practice. 2010; 59-66. PMid:23745064 https : //doi .org/10.2147/AMEP.S14100

[37] Schiavenato M. Re-evaluating simulation in nursing education: beyond the human patient simulator. Journal of Nursing Education. 2009; 48(7): 388-394. PMid:19634264 https://doi.org/10.3 928/01484834-20090615-06

[38] Lewis R, Stachan A, Smith M. Is high fidelity simulation the most effective method for the development of non-technical skills in nursing? A review of the current evidence. The Open Journal of Nursing. 2012; 6: 82-89. PMid:22893783 https://doi .org/10.2174/18 74434601206010082

[39] Neil M, Wotton K. High-Fidelity Simulation Debriefing in Nursing Education: A Literature Review. Clinical Simulation in Nursing. 2011; 7(5): 161-168.

[40] Shinnick M, Woo M, Horwich T, et al. Debriefing: The Most Important Component in Simulation? Clinical Simulation in Nursing. 2011; 7(3): 105-111. https://doi.org/10.1016/j.ecns. 201 0.11 .005

[41] Jordan S. Teaching pharmacology by case study. Nurse Education Today. 1997; 17(50): 386-93. https://doi.org/10.1016/S026 0-6917 (97) 80100-1

[42] Yoo MS, Park JH, Lee SR. The effects of case based learning using video on clinical decision making and learning motivation in undergraduate nursing students. Journal of Korean Academic Nursing. 2010; 40(6): 863-871. PMid:21336020 https://doi.org/10.4 040/jkan.2010.40.6.863

[43] McFetridge B, Deeny P. The use of case studies as a learning method during pre-registration critical care placements. Nurse Education in Practice. 2004; 4: 208-215. https://doi .org/10.1016/S147 1-5953(03) 00067-2

[44] Forsgren S, Christensen T. An Evaluation of the case method in nursing education. Nurse Education in Practice. 2014; 14(3): 164-9. https://doi.org/10.1016/j.nepr.2013.08.003

[45] D'Souza M, Venkatesaperumal R, Radhakrisnan J, et al. Engagement in clinical learning environment among nursing students: Role of nurse educators. Open Journal of Nursing. 2013; 3: 25-32. https://doi.org/10.4236/ojn.2013.31004 